\title{
ARTÍ́CULOS
}

\section{MEMORIA DE FRANCISCO PÉREZ CARBALLO Y JUANA CAPDEVIELLE DESDE LA TRANSICIÓN}

\author{
José Galán Ortega \\ Universidad Complutense de Madrid \\ ajosegalanortega@gmail.com
}

\section{The memory of Francisco Pérez Carballo and Juana Capdevielle since the Transition}

Recibido: 09/09/2016 - Aceptado: 13/10/2016

Cómo citar este artículo/Citation:

José GALÁN ORTEGA (2017), “Memoria de Francisco Pérez Carballo y Juana Capdevielle desde la Transición", Hispania Nova, 15, págs. 274-295.

DOI: https://doi.org/10.20318/hn.2017.3489
Copyright: (C) HISPANIA NOVA es una revista debidamente registrada, con ISSN 1138-7319 y Depósito Legal M 9472-1998. Los textos publicados en esta revista están -si no se indica lo contrario- bajo una licencia Reconocimiento-Sin obras derivadas 3.0 España de Creative Commons. Puede copiarlos, distribuirlos y comunicarlos públicamente siempre que cite su autor y la revista y la institución que los publica y no haga con ellos obras derivadas. La licencia completa se puede consultar en: http://creativecommons.org/licenses/by-nd/3.0/es/deed.es
Resumen: Desde la perspectiva metodológica de la historia sociocultural de la memoria, este artículo pretende indagar, fundamentalmente, en la memoria cultural de Francisco Pérez Carballo y Juana Capdevielle San Martín, proyectada por diferentes portadores del recuerdo desde la Transición hasta la actualidad. Ambas figuras han sido convertidas, junto a muchos otros vectores del cambio social frustrado por la violencia de un golpe de estado y de una dictadura, en símbolos ambivalentes de modernidad que contribuyen a forjar o reforzar determinadas identidades, subordinados a una idea de ciudadanía republicana. Esta idea converge, paso a paso, pero sin demora, con el discurso y los valores encarnados por importantes sectores intelectuales e ideológicos de la sociedad española en las últimas décadas.

Palabras clave: Francisco Pérez Carballo, Juana Capdevielle San Martín, Memoria cultural, Transición, II República, Guerra Civil, represión franquista.
Abstract: Deploying a sociocultural history of memory methodology, this article proposes to analyze the cultural memory of the historical figures of Francisco Pérez Carballo and Juana Capdevielle San Martín, conveyed by different memory carriers from the Transition to the present-day. I argue that this trajectory of memory has converted them, along with other vectors of social change frustrated by the violence of the coup d'état and the dictatorship, in ambivalent symbols of modernity who serve to forge or reinforce certain identities, subordinated to the concept of the republican citizen. This idea converges, progressively, with the speech and values embodied by important ideological and intellectual sectors of Spanish society in the last decades.

Keywords: Francisco Pérez Carballo, Juan Capdevielle San Martín, cultural memory, transition, Second Republic, Civil War, Francoist repression. 


\section{MEMORIA DE FRANCISCO PÉREZ CARBALLO Y JUANA CAPDEVIELLE DESDE LA TRANSICIÓN}

\section{INTRODUCCIÓN}

Francisco Pérez Carballo fue nombrado gobernador civil de A Coruña por el gobierno Azaña en abril de 1936. Esta designación constituyó, en parte, un reconocimiento político de la trayectoria precoz de un joven de veinticinco años, ya curtido en las lucha política y estudiantil iniciada en los últimos años de la dictadura de Primo de Rivera. Así, ocupó la presidencia de la Asociación Profesional de Estudiantes de Derecho/ FUE de Madrid (curso 1931-32) y representó a la organización fueista en congresos estudiantiles nacionales e internacionales, formó parte de la última directiva de la JAR y actuó como delegado de la JIR, durante el bienio rectificador, en el Consejo Nacional de Izquierda Republicana. Un reconocimiento, una distinción política, que compensaría el esfuerzo de un abogado (oficial letrado de las Cortes, profesor ayudante de prácticas en la cátedra de Derecho Romano de la Universidad Central), ateneísta y dirigente político y estudiantil procedente de una familia de emigrantes gallegos radicados en Madrid desde principios del siglo XX.

La ejecución del último gobernador republicano de A Coruña, el 24 de julio de 1936, tras encabezar la resistencia del Gobierno Civil a los golpistas, y de su esposa, la intelectual y bibliotecaria madrileña Juana Capdevielle -paseada, semanas más tarde, por un grupo de falangistas en las proximidades de Rábade (Lugo)-, propició que diferentes vectores de la memoria cultural, fundamentalmente, aunque intersectadas o complementadas por memorias políticas, profesionales o gremiales, rescatasen las figuras de ambos (y en parte sus biografías) para convertirlos en símbolos destinados a construir o reforzar determinadas identidades. Este proceso de recuperación memorial se inició tímidamente durante la transición a la democracia y entró en ebullición en la primera década del siglo XXI. Su objetivo se centró en subrayar el aura de modernidad que desprendían las trayectorias de Pérez Carballo y Capdevielle como ciudadanos cultos, dotados de una conciencia política y social diferenciadora y comprometidos, junto a tantos otros ciudadanos de la época, con la reconstrucción generacional de un país necesitado de amplias reformas estructurales. Por otra parte, su condición de víctimas ciertamente arquetípicas de la represión franquista (Capdevielle estaba embarazada cuando fue asesinada), generó el interés de grupos de intelectuales y escritores que, en los últimos años, han buscado referencias simbólicas e identitarias en un pasado condenado al olvido durante la dictadura y la Transición. Para estos portadores de memoria/as, la condición humana, intelectual o política de los sujetos individuales o grupales se situaba por encima de la relevancia social conferida a estos en el tiempo, una buena premisa también para acentuar la lucha por la dignificación de las víctimas del franquismo y la condena del régimen franquista y sus secuelas. Esta realidad contrasta con la escasa atención que la historiografía ha prestado a sus figuras, laguna especialmente notoria en relación al caso del último gobernador civil republicano de A Coruña y al de tantos servidores públicos del estado

HISPANIA NOVA., 15 (2017), págs. 274-295 
republicano, desperdigados por los gobiernos civiles y los órganos de administración local de la República española.

La resistencia de algunos sectores historiográficos a negar la sustantividad de la memoria, o de las memorias que no se revelen como estrictamente autobiográficas, puede compensarse, desde la perspectiva de una renovada historia de la memoria, con los usos metafóricos o el reflejo concreto de una abstracción. Sin embargo, esta estrategia cognitiva debe implicar la definición más exacta posible del sujeto que recuerda y de las condiciones del act of remembrance: la noción de memoria compartida. Esta idea se define como una inferencia expresada "por la vía oblicua de las metáforas", traducida en manifestaciones o artefactos culturales constituidos por las proyecciones del recuerdo ${ }^{1}$.

Por su parte, las memorias individuales se contemplarán aquí, a la hora de entroncar con la narrativa de memorias colectivas o culturales -como hace Halbwachs, pero sin negar el peso o la autonomía de la agencia individual $^{2}$ en la reconstrucción mediada del recuerdo-, como puntos de vista dinámicos sobre las diferentes memorias activadas. Puntos de vista interrelacionados entre sí hasta configurar relatos comunes, nunca idénticos. Memorias que fluyen y se remodelan continuamente, lejos de convertirse en simples depósitos de información, hasta reconfigurar las identidades propias o ajenas y el pasado en función de determinadas coordenadas mentales y sociales, para hacerlo así más inteligible en un proceso de aprendizaje continuo.

\section{Metodología.}

La memoria desempeña en la actualidad distintas funciones sociales, entre ellas, pues, la de reivindicación de un pasado que se quiere preservar y la conservación o reconstrucción de identidades. Las culturas de la memoria tratan de lograr un futuro con memoria -para ello han puesto el énfasis en los derechos humanos, la identidad de las minorías y de género y la revisión del pasado- y se han significado en procesos globales de regeneración democrática, que buscan expandir y fortalecer las esferas públicas de la sociedad civil ${ }^{3}$.

Para sintetizar las funciones sociales de la memoria colectiva (las múltiples memorias colectivas adheridas a un sujeto a través de sus pertenencias o adscripciones, todas ellas en continua evolución, selectivas, de textura sinuosa), estableceríamos un vínculo entre la capacidad de reflejar el pasado de los memory carriers y una necesidad colectiva de incorporar innumerables representaciones del mismo. Representaciones, imágenes, que cristalizarían en distintas prácticas culturales, fundamentalmente conmemorativas y simbólicas, en la forja de identidades relacionadas con determinados valores y en la transmisión del orden social y político vigente. Otros "trabajos de la memoria" necesitarían un análisis que aquí se reduce a una breve explicación, nos estamos refiriendo al silencio (piénsese en lo ocurrido en España durante la transición con respecto a la guerra civil y la posguerra: un silencio generoso, pero nunca un olvido) y al olvido en sí, que no se opone a la memoria como se cree ${ }^{4}$, pues la memoria es una

\footnotetext{
${ }^{1}$ Joel CANDAU, Memoria e identidad, Buenos Aires, Ediciones del Sol, 2001, pp. 25.

2 Maurice HALBWACHS, La memoria colectiva, Prensas Universitarias de Zaragoza, pp. 50; Lorraine RYAN, "Cosmopolitan memory and national memory conflicts: on the dynamics of their interaction." Journal of sociology, 50: 4 (2014), pp. 501-514.

${ }^{3}$ Andreas HUYSSEN, En busca del futuro perdido, México, FCE, 2002, pp. 37-38.

${ }^{4}$ Tveztan TODOROV, Los abusos de la memoria, Barcelona, Paidos, 2008, pp. 22
} 
forma de olvido y el olvido es una forma de memoria oculta ${ }^{5}$. El derecho al olvido es tan digno de consideración como el derecho a la memoria. Nietzsche ya advertía sobre la necesidad de liberarse de la abrumadora carga del pasado, aunque proponía una visión excesivamente utilitarista del mismo. En cualquier caso, esta idea puede ser rebatida desde un punto de vista ético o en función de principios y valores de justicia universal, pues el equilibrio entre el derecho de las víctimas a olvidar y el del resto de los ciudadanos a saber propone un dilema complejo, perturbador, pero muy necesario.

La memoria colectiva se compondría no sólo de recuerdos de individuos y colectivos (que nunca deben ser concebidos como la simple acumulación, o la suma total, de recuerdos de sujetos o grupos), sino que incluiría las construcciones y reconstrucciones del pasado constitutivo de la comunidad específica:

In today's societies, which no longer "societies of memory" (...), social memory refers no so much to living memory but to organized cultural practices supplying ways of understanding the world, and providing people with beliefs and opinions which guide their actions (...) Memory's essential role in social life is connected with the fact that "collective memory is part of culture's meaning-making apparatus"(...) Because the past is frequently used as the mirror in which we search for an explanation and remedy to our presentday-problems, memory is seen "as a cure to the pathologies of modern life" ${ }^{6}$.

Además, si en occidente la conciencia del tiempo se proyectó durante siglos hacia el futuro, en cierto modo hacia la utopía, en la actualidad se asiste a un fenómeno en el que, por un lado, las sociedades, los ciudadanos considerados colectiva o individualmente, asumen la tarea de responsabilizarse sobre el pasado y, por otro, se acusa a la cultura de la memoria contemporánea de amnesia, anestesia u obnubilación ${ }^{7}$.

Esta contradicción alberga, pues, una confusión conceptual frecuente. El interés actual por la memoria sería, en cierta manera, un interés por la historia, aunque incluiría el matiz de la voluntad finalista de intervenir en la realidad para reivindicar o legitimar derechos e intereses colectivos. El historiador fue durante muchos siglos el depositario de la memoria, un intérprete que gozaba del monopolio de la misma, como habitual instrumento del poder. La "historia-memoria", y en especial su última encarnación, la "nación-memoria", legitimaba el orden político y social y se encargaba de transmitir los valores necesarios para preservarlo, desempeñando, por tanto, un papel pedagógico indispensable. Pero la legitimación por el pasado, por la historia, en definitiva, ha cedido el paso ahora a la legitimación por el futuro ${ }^{8}$. Mientras, en paralelo, y a veces intersectando con determinadas inercias globalizadoras, grupos e individuos elaboran o refuerzan sus identidades a través de instrumentos como la memoria, cuya función narrativa resulta vital, en el plano más profundo (el de las mediaciones simbólicas de la acción), para la constitución de la identidad ${ }^{9}$. En estas coordenadas, Lorralne Ryan advierte que "as the notion of a uniform identity has become increasingly anachronistic, social and

\footnotetext{
${ }^{5}$ Andreas HUYSSEN, op. cit, pp. 23; y, como correlato de una tesis que rechaza la categorización negativa del olvido, Paul CONNERTON, "Seven types of forgetting", en Memory studies (2008), pp. 1-59.

${ }^{6}$ Bárbara MISZTAL, Theories of social remembering, Philadelphia, Open University Press, 2003, pp. 12-13.

${ }^{7}$ Andreas HUYSSEN, op cit, pp. 22.

${ }^{8}$ Pierre NORA, Les lieux de mémoire, Tomo 1, París, Gallimard, 1997, pp. XXV.

${ }^{9}$ Paul RICOEUR, La memoria, la historia, el olvido, Madrid, Trotta, 2003, pp. 116.
} 
cultural memory have been obliged to make provision for the incorporation of diverse and often opposing memories" ${ }^{10}$.

El peso del presente, su supremacía actual, influye de forma notoria en el interés desmesurado en la memoria y en la relativización de la historia. Predomina el enfoque basado en los criterios del convulso presente (el presentismo y sus innumerables proyecciones) y se cuestiona el método de la historia a la hora de tratar percepciones cambiantes, selectivas, constreñidas a lo que el grupo ha vivido. La memoria sería, desde esa perspectiva, "una forma de historia dotada de finalidad", guiada por un "interés" que no es el del conocimiento, sino el del ejemplo, el de la legitimidad, el de la polémica, el de la conmemoración, el de la identidad, aquello que Niestzche identificaba como los diferentes usos que se podían hacer de la historia"11. En todo caso, se percibiría como un fenómeno colectivo, aunque psicológicamente sea vivido de forma individual, un proceso subordinado a un presente totalizador, al que la memoria colectiva se adhiere mejor que al pasado, pues ésta es esencial para determinar cómo un grupo social se contempla a sí mismo ${ }^{12}$. En cierto modo, la omnipresencia del fenómeno memorístico induce a la sociedad a fijarse más en las memorias sectoriales que en la perspectiva histórica en sentido estricto. El auge de la memoria revelaría, por otra parte, la aparición de nuevos y más numerosos actores sociales, de nuevos protagonistas, prismas y puntos de vista, destinados a cuestionar, cuando no a superar, el espacio político e ideológico ocupado por el estado-nación y sus imperfectas formas democráticas durante tanto tiempo.

Por otra parte, la pujanza de la historia del tiempo presente, una escuela historiográfica que tiene como objeto de estudio fundamental la historia vivida (las grandes tragedias del siglo XX han democratizado la historia y han hecho al individuo y al grupo conscientes de su papel protagonista), ha contribuido a revitalizar la memoria, la fuente oral y el testimonio. Para P. Nora, esta inercia social e intelectual ha obligado a los historiadores a revindicar sin ambages el "derecho a la historia" ${ }^{13}$. En estos términos, el debate metodológico y contextual generado requiere una dialéctica complementaria y nunca excluyente, un diálogo abierto entre la historiografía y las diversas memorias en pugna, que contribuya también a esclarecer y coordinar -si es que esto es posible, más allá de una jerarquización rígida- el papel de cada actor implicado en el conocimiento del pasado.

Hasta el momento no se ha perfilado una tipología clara de las clases de memoria estudiadas por las ciencias sociales, ahora (al menos desde tiempos recientes) por la historia. No existe consenso al respecto, algo, por otra parte, lógico y saludable. Probablemente, no sería pertinente establecer definiciones categóricas cerradas cuando en un mismo sujeto, individual o colectivo, confluye una encrucijada de memorias (individual, colectiva o social, y dentro de éstas, familiar, política, cultural, religiosa...), ${ }^{14}$ pero sí se echa en falta un esquema teórico más sólido que proporcionase claves de interpretación más coherentes y precisas.

\footnotetext{
${ }^{10}$ Lorraine RYAN, “Memory, Power and Resistance: the Anatomy of a Tripartite Relationship." Memory Studies 4:2 (2011), pp.154-169.

11 Marie Claire LAVABRE, "Sociología de la memoria y acontecimientos traumáticos", en Julio ARÓSTEGUI y Francois GODICHEAU, Guerra civil: mito y memoria, Madrid, Marcial Pons, 2006, pp. 44.

${ }^{12}$ Margaret MCMILLAN, The uses and abuses of memory, Londres, Profile Books, 2009, pp. 48.

${ }^{13}$ Entrevista digital a Pierre Nora en La Nación (Buenos Aires), 15-3-2006.

${ }^{14}$ Josefina CUESTA BUSTILLO, La odisea de la memoria. Historia de la memoria en España. Siglo XX, Madrid, Alianza, 2008, pp. 91.
} 
Así, en muchos casos, se utilizan indistintamente expresiones como "memoria social", "memoria colectiva" o "memoria histórica", prefiriéndose esta última expresión a "conciencia histórica", que denotaría un conocimiento reflexivo de las cosas y se distanciaría así de esa facultad de recordar asociada al inconsciente, espontánea y siempre demasiado subjetiva. En este sentido, Paloma Aguilar ha esbozado un esquema o marco interpretativo que puede resultar muy útil al investigador que se adentra en este campo. Esta autora establece, con carácter provisional, los siguientes tipos:

Existen memorias individuales (las de los testigos o participantes en los hechos), memorias institucionales u oficiales (las impulsadas mediante políticas de la memoria, que pueden llegar a ser dominantes y tienden a ocupar un lugar privilegiado en el ámbito público) y memorias colectivas o sociales (en las que los miembros de un determinado grupo van construyendo relatos comunes sobre el pasado, partiendo del intercambio entre las memorias individuales y de la información acumulada del hecho en cuestión). En este último caso, los relatos que acaben recabando más apoyo serán los que se conviertan, por encima de una pluralidad de memorias sociales que siempre existirá, en memorias hegemónicas, que pueden llegar a competir, si son suficientemente compartidas, con las institucionales. Las memorias colectivas o sociales se irán convirtiendo en memorias históricas a medida que los testigos directos vayan desapareciendo. El uso metafórico del concepto de "memoria" está presente en todos los casos, salvo en el primero, el de la memoria individual ${ }^{15}$.

Un uso metafórico que es necesario ampliar y redefinir para el análisis de las manifestaciones de memorias colectivas o grupales como, por ejemplo, las culturales, sostenidas y propagadas por sujetos y vectores comprometidos con la elaboración o reconstrucción de identidades, o, en otras palabras, "the concretion of identity", a partir de lo que Jan Assman considera un "store of knowledge, from which a group derives an awareness of its unity and pecularity". Este autor incide, además, en la naturaleza poliédrica tanto de la memoria como de la idenidad: "every individual belongs to numerous such groups and therefore entertains numerous self-images and memories" ${ }^{16}$.

Y a la hora de tratar con los mitos, tan abundantes en el territorio de la memoria, debe señalarse el hecho de que lo real puede ser mitologizado de la misma manera que lo mítico puede engendrar fuertes efectos de realidad ${ }^{17}$. Conviene insistir aquí en el matiz diferenciador ${ }^{18}$ entre memoria (concepto que engloba y mezcla realidad, percepción y mito) y mito político (construcción subordinada a una funcionalidad efectiva: integradora, movilizadora o esclarecedora), indisociable de la realidad antropológica del ser humano y no reductible a la simple dicotomía entre racionalidad e irracionalidad $^{19}$. Esta distinción presentaría el mito político como una imagen creada por la conciencia colectiva, contenida dentro o vislumbrada en los márgenes de los grandes relatos construidos por las distintas memorias, pero siempre sacralizado y no fundamentado en una realidad objetiva.

\footnotetext{
${ }^{15}$ Paloma AGUILAR FERNÁNDEZ, Políticas de la memoria y memorias de la política, Madrid, Alianza, 2008, pp. 6364.

${ }^{16}$ Jan ASSMANN, “Collective memory and cultural identity”, en New German Critique no 65 (1995), pp. 127 y 130.

${ }^{17}$ Andreas HUYSSEN, op cit, pp. 21.

${ }^{18}$ Duncan BELL, "Mythscapes: memory, mythology, and national identity", en British journal of sociology, Vol 54, no 1 (marzo 2003), pp. 63-81; Nora RABOTNIKOF, "Mito político y memorias de la política", en María Inés MUDROVCIC, Pasados en conflicto. Representación, mito y memoria, Buenos Aires, Prometeo, 2009, pp.105-24.

${ }^{19}$ Alberto REIG TAPIA, La cruzada de 1936, Alianza Editorial, 2008 (ebook), en especial posición. 2900-27.
} 
Por lo tanto, en las páginas que siguen se prioriza la búsqueda de respuestas a cuestiones como qué, por qué y cómo se recuerda, o se generan memoria o mitos, sobre la tarea de discernir el grado de fidelidad de cada relato memorístico a la realidad objetiva de la que se partiría, de cada presente del pasado ${ }^{20}$, sea este configurado con un carácter legitimador, reivindicativo o pretendidamente neutro. En esta labor, nos fijaremos también en los portadores de memoria o memory carriers como los concibe $\mathrm{H}$. Rousso en su obra de referencia, The Vichy Syndrome, tan relevantes en el debate social en la actualidad. Este autor entiende por carrier "any source that proposes a deliberate reconstruction on a event for a social purpose" ${ }^{21}$.

\section{DE LA TRANSICIÓN A LA ACTUALIDAD: LA MEMORIA Y SUS CAMINOS, EL DISCURSO DE LAS METÁFORAS.}

A partir de los años setenta, el recuerdo de Francisco Pérez Carballo se proyectó, inicialmente, en las memorias de exiliados retornados o antiguos compañeros de estudio o profesión con quienes el abogado madrileño mantuvo algún tipo de vínculo personal. En los últimos años, sin embargo, su figura ha sido reivindicada por determinados portadores de la memoria cultural: escritores, profesores universitarios, bibliotecarios, fundamentalmente. La mayoría de ellos se ha centrado en el valor simbólico y metafórico de la pareja formada por él y por su esposa, Juana Capdevielle, dos republicanos jóvenes, cultos, comprometidos con la modernidad y la ley que debía sustentarla, asesinados también prematuramente. que encarnarían a la perfección la impronta intelectual y el destino trágico, doloroso, de la República.

Durante la transición, el peso de la memoria negativa de la II República y la guerra civil, traducido en el temor espontáneo o inducido a un nuevo enfrentamiento entre españoles, se reflejó en un diseño institucional bien meditado. Un diseño que se alejó del modelo ensayado durante la II República (la ley electoral, el parlamento bicameral, la forma de estado en sí), en la actitud de todos los actores políticos, independientemente de las posiciones ideológicas defendidas, y en la consideración del pacto como medio esencial para resolver cualquier obstáculo en el proceso de reconstrucción de la democracia en España.

Sin embargo, en la actualidad, surgen miradas retrospectivas que expresan juicios críticos sobre ese periodo - provenientes, en esencia, de los movimientos políticos y sociales emergentes y de las asociaciones de recuperación de la memoria histórica, muy activas en la actualidad- y, en particular, denuncian la imposición de silencio u olvido, de un tipo particular de amnesia social derivada del proceso constituyente iniciado tras la muerte de Franco.

La impugnación creciente de lo que se considera un importante borrón en la transición política española, esto es, el olvido de las víctimas republicanas de la guerra civil y el franquismo en aras de la superación del difícil contexto político, contrastaría, sin duda, con la supervivencia de una memoria negativa del periodo republicano. Esta memoria proscrita, claramente instrumental, es interpretada por los sectores críticos con el discurso impuesto en la Transición -ahora en franco declive- como un tipo

\footnotetext{
${ }^{20}$ Josefina CUESTA BUSTILLO, op. cit, pp. 48.

${ }^{21}$ Henry ROUSSO, The Vichy Syndrome. History and memory in France since 1944, Cambridge, Harvard University Press, 1991, pp. 218.
} 
evidente de amnesia colectiva, y no tanto como el efecto de un complejo proceso de aprendizaje de las lecciones del pasado.

Cuando se habla del olvido o del silencio inducido desde las élites del país, pero aceptado tácitamente por la sociedad en su conjunto ante la inestabilidad de la época (crisis económica de los años 70 , recrudecimiento de la ofensiva de ETA, ruido de sables antes y después del golpe de estado del 23 de febrero de 1981), que no propiciaría la adopción de medidas de justicia transicional o de pública rehabilitación de las víctimas del franquismo, se quiere significar otra cosa, seguramente una legítima reivindicación de justicia moral inserta en la dinámica de relevo generacional:

Lo que se trata de denunciar en dicho contexto es que no se ha investigado públicamente el pasado (mediante el equivalente a una comisión de la verdad), que no se ha juzgado a los responsables de los delitos de violaciones de los derechos humanos cometidas al amparo de la dictadura (que ni siquiera se les ha identificado a través de un informe que habría podido emanar de la citada comisión), que no se ha prestado suficiente atención a las víctimas del franquismo ni a sus familiares (ni se les ha rendido el homenaje que merecen, ni se ha realizado esfuerzo alguno por recopilar sus testimonios) y, finalmente, que las autoridades, al permitir la impunidad de los victimarios, no han creado el clima propicio para que las víctimas sean capaces de sobre ponerse al miedo que les ha atenazado durante tantos años, y al trauma derivado de la persecución y la violencia, lo que explicaría que no pocos se hayan sumido en el silencio ${ }^{22}$.

Asimismo, las miles de fosas comunes aún por exhumar, la insuficiencia de las medidas de reparación material tomadas desde los inicios de la transición (diseñadas para equiparar derechos entre vencedores y vencidos, no para reconocer la condición de víctimas de los últimos, al emanar de la capacidad discrecional del Estado de decretar medidas de gracia), la resistencia al reconocimiento simbólico y moral de la causa de los republicanos y antifranquistas --no hay monumentos nacionales al conjunto de las víctimas de ambos bandos, ni lugares de memoria en el calendario, importantes símbolos del franquismo permanecen inalterables, no ha habido anulación de procesos judiciales de raíz política- y la escasa concreción de los poderes públicos (y de partidos como el PP) en la condena del franquismo son factores altamente significativos. Entre otras cuestiones, ayudarían a explicar que, desde la perspectiva de las víctimas y de buena parte de la sociedad española, se considere superado el "pacto de silencio" y se demanden fórmulas para resolver la cuestión de las memorias y los derechos sociales y políticos ignorados.

Desde esta perspectiva, el silenciamiento o secuestro de la memoria histórica (esa forma de historia dotada de finalidad para intervenir y modificar así la realidad) no concluiría con la promulgación de determinadas medidas legislativas, adoptadas paulatinamente en varias direcciones y escalas (la Ley de memoria histórica en 2007 , por ejemplo), muy controvertidas y limitadas en todo caso. Y, en estas coordenadas, la escasa permeabilidad social al trabajo de la historiografía en las últimas décadas constituye un factor más de incertidumbre con que enturbiar algunas fases de este proceso de reinterpretación del pasado.

Otra arista de este complejo problema estribaría en la pujanza actual de la memoria y del discurso de auto-justificación franquista -la existencia de múltiples memorias históricas parciales revela, entre ellas, la heredada del régimen anterior-, ante el que sólo valdría un continuado esfuerzo pedagógico y la neutralización de los usos invasivos o manipuladores de determinadas narrativas. En

\footnotetext{
${ }^{22}$ Ibidem, pp. 69-70.
} 
cualquier caso, la historiografía debe contemplar, desde un enfoque primordial basado en el conocimiento crítico, las legítimas demandas de las memorias en juego y abrirse al debate sobre los diversos modos de aproximarse al pasado, consciente de las limitaciones inherentes al trabajo científico (pero, en ningún modo, excluyente) de los historiadores.

Este es el contexto en el que en estos últimos años algunos investigadores e intelectuales, en representación de esa sensibilidad colectiva insatisfecha con el tratamiento público a las víctimas republicanas, han asumido, como vectores de una potente memoria cultural, la reivindicación de algunas figuras (caso de Francisco Pérez Carballo y Juana Capdevielle en la actualidad), instituciones o símbolos condenados primeramente al olvido. Para llevar a cabo esta tarea, han proyectado sobre la sociedad una nueva y legítima relectura del pasado en función de distintas inercias del presente.

Las primeras memorias individuales o colectivas que durante los años setenta y ochenta del pasado siglo hicieron visible, aunque tangencialmente en la mayoría de los casos, la imagen de Francisco Pérez Carballo fueron las de antiguos correligionarios y compañeros suyos, que escribieron acerca de sus experiencias vitales y políticas en España y el exilio. Aquí debe recordarse, para hacer inteligibles determinadas abstracciones, que el complejo tránsito o la conexión entre la memoria individual y la colectiva podría simplificarse, de forma sensible -como apunta Jay Winter-, specifying agency, esto es, definiendo con claridad quién recuerda y cómo, cuándo, dónde se produce ese act of remembrance ${ }^{23}$. Significativamente, Winter utiliza este último término para evitar el abuso semántico del concepto memoria.

Santos Martínez Saura, secretario particular de Azaña, comenzó a escribir sus memorias políticas durante los años setenta en su exilio mexicano. Su estilo elocuente e irónico, un tanto excesivo en algunos pasajes, nos acercó con notable agudeza a la figura política de Azaña y al contexto histórico de una coyuntura decisiva. De Francisco Pérez Carballo, uno de los miembros de las Juventudes de IR con más proyección profesional y política, Martínez Saura refería únicamente, aunque sin ahorrarse adjetivos, el hecho de su muerte y la de su esposa, tendencia acusada en la percepción social de su biografía por parte de las memorias individuales y colectivas de varias generaciones, independientemente de la ideología de quién recuerda. Lo hacía en estos términos:

Otra salvajada más que cometieron allí los facciosos fue el fusilamiento del gobernador civil Pérez Carballo y de su mujer Juana Capdevielle, licenciada en Filosofía y Letras y archivista de la Facultad de Madrid, acababa de casarse y estaba embarazada, ambos eran miembros destacados de la FUE y quizá por ello señalados por el odio de aquellas bestias ${ }^{24}$.

Más extenso y complejo es, sin duda, el recuerdo de Pérez Carballo en la memoria de Francisco Ayala. Como estudiantes de edades relativamente próximas, fueron compañeros en la facultad de Derecho de la Universidad Central de Madrid, que, en los últimos años de la dictadura de Primo de Rivera, y durante el gobierno Berenguer, vivió tiempos de agitación estudiantil y fuerte coacción gubernamental. Coincidieron también en el claustro de profesores de esta facultad a partir del curso 1933-34, fecha de la incorporación de Pérez Carballo al mismo: Ayala como auxiliar de Derecho Político (y secretario de la facultad) y Pérez Carballo como ayudante de prácticas de Derecho Romano. De forma

\footnotetext{
${ }^{23}$ Jay WINTER, Remembering war: The Great War between Memory and History in the twentieth century (edición digital Kindle), posición 55.

${ }^{24}$ Santos MARTíNEZ SAURA, Memorias del secretario de Azaña, Madrid, Planeta, 1999, pp. 459.
} 
paralela, ambos se presentaron y aprobaron en la misma convocatoria la oposición a oficial letrado del Congreso de los Diputados, tomando posesión de sus respectivos cargos en marzo de 1933. Como reconoció Francisco Ayala en Recuerdos y olvidos, mantuvo una particular relación de amistad con varios de sus compañeros del Cuerpo de Letrados del Congreso. Entre ellos, citaba los nombres de Jesús Rubio, Segismundo Royo Villanova, Medina Echavarría y el propio Pérez Carballo, "un gallego muy joven -creo que el más joven de nuestra promoción- y muy ambicioso, a quien fusilarían los rebeldes en La Coruña, donde era gobernador, a la vez que asesinaban a su esposa en cinta" ${ }^{25}$.

El recuerdo de su antiguo compañero Pérez Carballo afloró de nuevo cuando Francisco Ayala, en el mismo libro, rememoraba su regreso a España, ya iniciada la guerra civil, y su posterior reincorporación a la Secretaría del Congreso de los Diputados, en un Madrid asediado por los bombardeos fascistas. El reencuentro con Jesús Rubio, quien permanecía en activo dentro del cuerpo de oficiales letrados del Congreso (dos décadas más tarde ministro de Educación con Franco), quizá su amigo más íntimo en aquella época, dio paso a frecuentes citas y, en sus conversaciones, a la evocación de antiguos compañeros:

Solíamos compartir tanto algunos placeres artísticos (el tocaba muy bien el piano y con frecuencia iba a tocarlo también a mi casa), como las bromas a expensas de algunos de nuestros compañeros, del ambicioso y caviloso Pérez Carballo, del ingenuo Rodríguez (que, siendo marxista, se aplicaba con ahínco al estudio del Derecho Mercantil para ser catedrático de la asignatura) y de los amigos falangistas, a cuya tertulia de la Ballena Alegre nos asomábamos alguna vez..." 26.

El mismo año de la primera edición de Retratos y olvidos, Rosario Hiriart publicaba Conversaciones con Francisco Ayala en la Colección Austral. Cuando la autora le preguntó al escritor granadino si tomó parte activa en la vida política durante los años anteriores a la República o durante ésta, Ayala se mostró tajante en su respuesta:

--Pues, según le decía, la actividad política en ese sentido me ha resultado siempre inadecuada a mi temperamento y aficiones (...) En un sentido amplio, ¿quién no hace política? Vivir es hacer política, tanto en el plano nacional e internacional como en el personal, pues la vida humana es histórica y el motor de la historia es la política. Pero yo nunca tuve la ambición de poner las manos en las palancas del mando... Recuerdo la extrañeza que me causaba el afán de un compañero mío en el cuerpo de Letrados del Congreso, un muchacho muy joven, gallego, Pérez Carballo, que deseaba ardientemente entrar en el juego político, y consiguió en efecto ser nombrado gobernador civil de La Coruña a raíz de triunfar en las elecciones el Frente Popular. Al infeliz, el logro de esa ambición le costó la vida pues a él y a su mujer, embarazada, los asesinaron los sublevados: pero ese destino me conmovió de una manera muy especial pues yo había presenciado con estupefacción sus afanes, para mí incomprensibles, de lograr el cargo donde le aguardaba la muerte. Estupefacción, digo, por ser algo tan radicalmente ajeno a mí naturaleza que apenas podía comprenderlo. Es una incapacidad mía de la que no alardeo, pues sé muy bien que constituye una seria limitación ${ }^{27}$.

Como ponen de manifiesto los fragmentos citados, Francisco Ayala reconocía sin ambages su aversión por la acción política y su renuncia a un compromiso activo con las instituciones y el poder,

\footnotetext{
${ }^{25}$ Francisco AYALA, Recuerdos y olvidos, Madrid, Alianza, 2006, pp. 161.

${ }^{26}$ Ibidem, pp. 197.

${ }^{27}$ Rocio HIRIART, Conversaciones con Francisco Ayala, Madrid, Espasa-Calpe, 1982, pp. 60-61.
} 
cuestión sobre la que reflexionó en sus escritos ensayísticos. Quizá como teórico del derecho político, como pensador inclinado hacia un "liberalismo esencial", recelaba de la ambición política, por otra parte legítima, de la cohorte que rodeaba a Azaña y de la adopción por este último de ciertas estrategias o decisiones críticas, como su abandono de la presidencia de gobierno para asumir la de la República. De cualquier modo, la lucidez de su escritura, su capacidad de sintetizar procesos políticos e históricos complejos, contrastaba con la crítica de compromiso político que encarnaría, en este caso, un joven ciudadano como Pérez Carballo. En este punto, el joven abogado madrileño estaba decidido a emprender una carrera política y docente, voluntad de participación en la vida pública que Ayala vislumbraba más como una exhibición de ambiciones personales, aun sin negarle a este tipo de desviación un simbolismo democrático evidente.

Por su parte, Emilio González López, discípulo de Luis Jiménez de Asúa, profesor de Derecho Penal en varias universidades españolas y, ya en el exilio, de Historia en el Hunter College de New York, fue secretario general de la FUE durante la dictadura de Primo de Rivera y, más tarde, diputado a Cortes por la ORGA e Izquierda Republicana. Desde esa perspectiva, conoció a Francisco Pérez Carballo como miembro de la FUE y alumno de la facultad de Derecho de la Universidad Central de Madrid, de la que González López fue profesor auxiliar en la cátedra de Derecho Penal.

La noche del 18 de julio González López se encontraba en el edificio de Telefónica en Madrid, junto a su cuñado Emilio Morayta, consejero del gobierno en la compañía, desde cuyo despacho pudo mantener comunicaciones telefónicas, entre otros interlocutores, con muchos gobernadores civiles. A estos últimos los encontró desorientados y llenos de incertidumbre ante la gravedad de la situación y la imprevisión y negligencia que habría demostrado, según esta versión, el gobierno de Casares Quiroga desde un primer momento. Para González López, la inoperancia y la improvisación gubernamental tuvo mucho que ver con la actitud personal de Casares Quiroga -en teoría, su indecisa y premiosa manera de hacer política-, en quien carga la responsabilidad principal en la falta de un plan de actuación contra conspiradores y golpistas, coordinado entre el gobierno, los gobernadores civiles y los distintas fuerzas policiales y militares. De su experiencia en las conversaciones mantenidas con los gobernadores civiles, subrayaba el caso de Pérez Carballo:

Con el gobernador de La Coruña, mi antiguo discípulo Francisco Pérez Carballo, Oficial Letrado del Congreso, hablé varias veces en esa noche angustiosa; y pude comprobar su desorientación e incertidumbre, su falta de preparación, de instrucciones y de fuerzas para enfrentarse con los rebeldes (...) Los gobernadores civiles, muchos de los cuales, entre ellos los de Galicia, pararon con su vida su incertidumbre y su desorientación, que no era la suya, sino la del gobierno, parecían irresolutos y perdidos en medio de una gran confusión (...) Y de todos los gobiernos civiles con los que hablé fue en el de La Coruña en el que el gobernador era víctima de esa total falta de preparación por parte del gobierno de un plan en el que se coordinaran las fuerzas militares leales, sobre todo las de los guardias de Asalto, con las civiles ${ }^{28}$.

Las críticas de González López al gobierno republicano, y su ajuste de cuentas con la figura de Casares, se insertan en la memoria negativa fraguada, desde muy diversas posiciones ideológicas e intelectuales, en torno a la personalidad política y humana del presidente del gobierno que debió afrontar la sublevación militar. El silencio mantenido por Casares Quiroga durante la guerra, el exilio y

\footnotetext{
${ }^{28}$ Emilio GONZÁLEZ LÓPEZ, Memorias de un diputado republicano en la guerra civil española (1936-1939), Sada (A Coruña), Edicións do Castro, 1990, pp. 17-18.
} 
hasta su muerte contribuyó, sin duda, a aumentar su particular leyenda negra, que se extendió, en cierto modo, a los que se consideró como sus discípulos o colaboradores más cercanos. Se gestaría así el mito del perfecto chivo expiatorio del bando republicano, excluyente de cualquier matización destinada a explicar esa aparente inacción gubernamental en términos de una estrategia apaciguadora, de un plan consensuado para evitar cualquier tipo de provocación a las fuerzas antirrepublicanas. Distinto es el caso de Francisco García Valdecasas, amigo de Pérez Carballo desde los tiempos del instituto Cardenal Cisneros y de la Universidad Central, donde estudió Medicina, se especializó en Fisiología y fue discípulo de Negrín, mucho antes de significarse, como catedrático de Farmacología y rector de la Universidad de Barcelona (1965-1969), en la política represiva contra el movimiento estudiantil de esta ciudad. Al recordar sus vivencias durante la guerra civil, en una entrevista concedida a una publicación de la Real Academia de Medicina de Catalunya en 2003, la memoria de García Valdecasas se detuvo en el recuerdo de Francisco Pérez Carballo, reflejo de una vieja amistad truncada por la contienda civil, para resaltar el modelo de actuación de un representante del poder civil frente a la rebelión militar franquista:

Jo tenía un amic, molt bona persona, que es deia Francisco Pérez Carballo, fill d'un humil maquinista de la Renfe, però amb un cap extraordinari que als 25 anys havia acabat la carrera de dret i havia guanyat oposicions a lletrat del Consejo de Estado i que a les Cortes era un dels homes més significants. El juny del 36, el ministre de la governació el va nomenar gobernador civil de La Corunya. El 16 de juliol jo em sentía molt disgustat perquè no havia tingut èxit en unes oposicións a cátedra que m havien anat força bé, i amb una amigueta meva ens en va manar a casa d'aquest amic meu i la nostra arribada va coincidir amb I'Alzamiento Nacional. El meu amic, molt integre i bona persona, es va enfrontar amb els rebles, que el van empresonar. Alguns sindicalistes se li van oferir per ajudar-lo atacant els caps militars $i$ immovilizant-los, però ell no va voler i, l'endema, un consell de guerra el va condemnar i el van afusellar. Por cert, a la seva dona, que era dun geni molt viu, la van matar sense cap judici previ ${ }^{29}$.

Como ya hemos señalado paginas atrás, la deuda moral y material que la sociedad española contrajo con las víctimas republicanas de la guerra civil y el franquismo está, en realidad, lejos de ser saldada. Esta deuda pendiente, que ha impedido durante años la verdadera cicatrización de las heridas del pasado, está siendo transferida en la actualidad, una vez superadas casi por completo las razones que inducían al silencio, a las siguientes generaciones como un legado simbólico irrenunciable. La todavía vacilante respuesta institucional al desafío de la memoria, entendida como la percepción presente de un determinado pasado sustentada por una parte importante de la sociedad, ha generado una creciente insatisfacción entre un amplio sector de la ciudadanía, adscrito fundamentalmente a posiciones ideológicas de izquierda -desde los partidos tradicionales a las fuerzas emergentes y los nuevos movimientos sociales y ciudadanos- o nacionalistas, desde las que también se cuestiona de forma transparente el relato heredado de la Transición y el sistema político vigente.

Este malestar se manifiesta, por ejemplo, en el papel creciente de la memoria cultural en la reivindicación de los vencidos, de los olvidados, ante la lentitud de gobierno e instituciones en satisfacer plenamente las demandas de justicia moral y material para las víctimas de la represión franquista, incapaces de asimilar una realidad marcada por la pluralidad de las memorias políticas latentes. A estas

\footnotetext{
${ }^{29}$ Antoni CARALPS, "Retrat de metges: Francisco García Valdecasas", en Annals de Medicina, Vol 86, n 4 (octubre/noviembre/ diciembre 2004), pp. 4.
} 
memorias veladas o ignoradas ${ }^{30}$, hay que añadir la dificultad de contrarrestar el peso o, directamente, la vigencia de algunos puntos del discurso y la visión histórica elaborados por el franquismo, y reconstruidos ad hoc en la transición. Parece evidente que la historia no puede retroceder como proceso global y revela efectos permanentes entre los cimientos de una comunidad política, constituida por varios grupos generacionales que vivieron su proceso de socialización bajo una dictadura.

Pero lo que importa aquí es constatar que esta memoria cultural o estas memorias culturales existen, que sus portadores son esos puntos de vista dinámicos que vertebran cualquier tipo de memoria colectiva y evolucionan paulatina e inexorablemente hacia la reconstrucción o el reforzamiento de identidades cara a un futuro considerado como inminente. Entre ellas, y situada en un plano principal, se halla la republicana, concebida como instrumento de legitimación del papel de los nuevos y viejos actores de un cambio social, político y cultural pensado para derribar el contra-modelo democrático global imperante, y no sólo en función de las dudas del poder político en reconocer los agravios del pasado o afrontar los evidentes obstáculos hallados en su nueva relación con un medio social renovado y complejo.

Y lo que hemos denominado "memoria cultural" (en puridad, las distintas memorias culturales) lleva tiempo expresándose en novelas, relatos, ensayos, películas, documentales, obras teatrales, exposiciones y otras manifestaciones artísticas y culturales conducidas por los denominados portadores de memoria, o memory carriers. Esta memoria cultural interactúa con una determinada memoria histórica, al implicar una finalidad ejemplarizante, legitimadora o reivindicativa, visibles especialmente en la voluntad de construir o reforzar identidades para enfrentar un contexto político o cultural que se impugna y se quiere modificar.

En el caso de Juana Capdevielle y Francisco Pérez Carballo, la memoria o las diversas memorias culturales, a espaldas de las instituciones hasta tiempos recientes, ha rescatado gradualmente sus figuras del olvido y las ha elevado a la categoría de metáforas colectivas, de símbolos que encarnan a la joven República malograda.

En el proceso de recuperación de la memoria de Francisco Pérez Carballo y Juana Capdevielle, destaca la labor de los escritores y profesores universitarios Claudio Rodríguez Fer, director de la cátedra José Ángel Valente de la Universidad de Santiago de Compostela y autor del poemario Tigres de ternura, y Carmen Blanco, quien desde una perspectiva feminista (orientada hacia el vínculo entre la mujer, la literatura y las relaciones de poder y armonía entre sexos) ${ }^{31}$, ha reivindicado y homenajeado con especial intensidad la memoria de ambos en textos de diversa naturaleza. Hay que señalar que ambos autores no se han limitado a una reconstrucción muy personal, a través de la escritura poética, de la memoria de los republicanos represaliados durante la guerra civil y el franquismo. En este sentido, promueven desde hace años las actividades de la Asociación para a dignificación das víctimas do fascismo, de la que C. Rodríguez Fer es uno de sus directivos, y coordinan la revista Unión Libre. Cadernos de vida e culturas, editada por Edicións do Castro, que ha dedicado siempre un espacio central a las voces e historias personales de las víctimas de la represión franquista, con números especiales y monográficos como Vermellas (no 11, 2006).

\footnotetext{
${ }^{30}$ Lorraine RYAN, Memory and Spatiality in Post-Millennial Spanish Narrative. Sussex: Ashgate.2014, pp. 25.

${ }^{31}$ Una buena referencia para el análisis de la memoria feminista se encuentra en Marianne HIRSCH and Valerie SMITH, Gender and Cultural Memory, Special Issue of Signs: Journal of Women in Culture and Society , 28, 1, (2002).
} 
Quizá el más significativo de los homenajes literarios de Carmen Blanco al matrimonio Pérez Carballo esté contenido en Atracción fatal, un libro difícil de clasificar, una indagación sobre temas tan presentes en el lenguaje poético como la belleza o el amor, que también explora la memoria individual y la de las víctimas de la guerra civil y el franquismo. En palabras de la autora:

Unha obra caleidoscópica e fragmentaria feita con fragmentos que son historias e historias construidas con fragmentos, é dicir, confeccionada con distintos fragmentos de vida máis ou menos relacionados entre sí (...) A súa estructura é a do del patchwork ou a da colcha de fargallos que cómpre ler como un tapiz, cunha historia central, quizais a dos amantes de Augas Santas ou tamén a de Xoana Capdevielle ${ }^{32}$.

Y es la memoria rescatada de Juana Capdevielle, una intelectual republicana alejada de una militancia política concreta, la que, como tantas veces en los últimos años, nos lleva a la de su marido, el gobernador civil de A Coruña, y no a la inversa como en décadas anteriores -la imagen de Juana se contemplaba en función de su ascendente y vinculación a su marido-, para constituir en el recuerdo un reflejo más del legado republicano de modernidad y esplendor intelectual. Un legado consistente, indeleble, que ni la guerra civil ni la dictadura consiguieron borrar en esencia.

Fundamentalmente, el texto iluminaría, con el acento poético que enfatiza el mensaje de carácter político o social y desafía la mirada crítica de los historiadores, el papel relevante de Juana Capdevielle en la memoria resistente y la responsabilidad asumida por la autora en la reivindicación de su figura y en su elevación paulatina, ya rehabilitada a través de la palabra, al imaginario de la memoria colectiva. Este es el quizá el más importante de los fragmentos que Carmen Blanco le dedica a la esposa de Pérez Carballo:

\section{Juana Capdevielle.}

Hoxe vimos só dous amantes solitarios pasear os foxos de Rábade que acolleron tenros o teu corpo $e$ visitar silenciosos a túa tumba solitaria, mais prométoche, Juana Capdevielle, que, como xa está o teu nome na memoria resistente antifascista, estará tamén un día na memoria comunal de todos coa máxima dignidade, que é a das víctimas insubmisas acosadas, torturadas e asesinadas pola prepotencia do poder fascista ${ }^{33}$.

A partir de este pequeño texto surgen otros dedicados de forma sintética a los últimos días en la vida de Juana, desde su salida apresurada del Gobierno Civil de A Coruña, al inicio de las hostilidades, hasta su muerte gallega, y a perfilar definitivamente su retrato de mujer culta y progresista. De este modo, Carmen Blanco desempeña la función de "memory carrier" y, a pesar de desvelar todo el engranaje poético por medio de una excesiva identificación personal, contribuye, a través de la práctica de la memoria cultural, a la recuperación de principios y valores compartidos a lo largo del tiempo. En otras palabras, el aura de modernidad que tanto Francisco Pérez Carballo como Juana Capdevielle proyectaron en los críticos años treinta son transformados ahora, de ese modo, en símbolos y referencias personales y colectivos, en aras de una nueva sociedad posible.

Veamos algunos otros fragmentos especialmente significativos a lo largo de estas páginas, tejidos con una vocación minimalista. El primero, la nueva identidad gallega de Juana (madrileña de padre francés y madre navarra), cuya conexión con Galicia se forjó realmente en sus últimos meses de

\footnotetext{
${ }^{32}$ Carme BLANCO, Atracción total, Vigo, Xerais, 2008,, pp. 13-14.

${ }^{33}$ Ibidem, pp. 152.
} 
vida en A Coruña y tras su muerte e inhumación en el cementerio de Rábade, a escasos kilómetros de la ciudad de Lugo. Esta íntima adopción post-mortem trascendería, probablemente, el lenguaje poético y sus posibles lecturas políticas -en clave de silencios y olvidos oficiales 0 , en otro sentido, desde la sensibilidad nacional- para expresar un sentimiento intenso hacia Juana -un puente entre identidades abstractas que se refuerzan mutuamente-, adoptada simbólicamente como hija de la tierra que la vio morir:

\section{Galega por la morte}

Desde que chegaches a Galicia temiches sempre, con fundamento, pola vida do teu home, mais non imaxinaches ata ao final que a ti mesma te farían galega pola norte ${ }^{34}$.

En el segundo, hay una referencia al mito de una Juana Capdevielle resistente dentro de los muros del edificio del Gobierno Civil, que es convenientemente matizado:

\section{Atendendo os feridos}

Aínda que ti eras xa unha refuxiada, a mente mítica dos dous bandos imaxinábate en pé xunto ao teu home na defensa do Goberno Civil atendendo os feridos ${ }^{35}$.

Y en el siguiente aparece un retrato que revela a la joven precursora, a la mujer intelectual, trabajadora y moderna que contribuía al cambio social, a la víctima finalmente (sujeto, por lo tanto, de una necesaria reivindicación y dignificación), hallada en la memoria junto al hombre con el que compartió todos esos valores. La imagen simbólica perfecta, por otra parte, para apoyar el discurso contra las huellas latentes en la sociedad actual del poder ilegítimo de una dictadura:

\section{Mulleres cultas e progresistas.}

Juana foi unha bibliotecaria que participou moi activamente na alta cultura madrileña da República desde o seo da Universidade e do Ateneo. Pertenceu ao grupo de mulleres cultas e progresistas que estaba cambiando coa súa existencia consecuente a vida pública e privada do país. Estivo afanada nas súas tarefas intelectuais e tardou en coñecer a un home que lle gustase por todo. Cando o encontrou casou con el e ao pouco tempo a parella ven vivir a Galicia, cando o home se puxo á fronte do Goberno Civil da Coruña, por cuxa defensa perdería a vida ${ }^{36}$.

Juana Capdevielle y su marido, Francisco Pérez Carballo, pertenecen a una generación que representa, en su experiencia colectiva -desde esta visión-, uno de los símbolos más brillantes de la República, entendida no sólo como una forma de estado verdaderamente democrática, sino como un modo de concebir e interpretar el mundo desde una perspectiva intelectual dinámica y transformadora. El recuerdo colectivo o la evocación de sus figuras y biografías nutrirían la identidad personal y colectiva que, desde la óptica de la memoria cultural republicana emergente desde el inicio del siglo XXI, sustentaría un modelo social y cultural muy distinto del patrocinado por el sistema político vigente al amparo de la monarquía postfranquista. Un legado traducido en el brillo intelectual de hombres y mujeres jóvenes, capaces de asegurar el futuro de un cambio social en marcha y, por ello, acechados por las fuerzas reaccionarias:

\footnotetext{
${ }^{34}$ Ibidem, pp. 155.

35 Ibidem, pp. 157.

${ }^{36}$ Ibidem, pp. 158.
} 


\section{DAS MELLORES COUSAS DA REPÚBLICA}

A parella Francisco Pérez Carballo e Juana Capdevielle formaba parte das mellores cousas da República. o fascismo non puido soportar o brillo das súas figuras e liquidounos aos dous ignominiosamente. Mais na historia do progreso quedarán para sempre ${ }^{37}$.

Y estos referentes están siendo recuperados por los que se han convertido voluntariamente en portadores de su memoria, expresión de la ilusión republicana, con el fin de extraer los valores contenidos en ella y fijarlos en una ética social capaz de influir en el presente y proyectarse en el futuro. Valores democráticos, republicanos, ciudadanos, constitutivos de la dignidad del individuo, restablecidos ahora por analogía con la modernidad y el progreso social invocados, mediante el trabajo de las memorias sociales y culturales. Así pues, el caso que nos ocupa se podría entender mejor en el contexto de un proceso global protagonizado por la memoria colectiva:

By mediating and paring the past and the present, as well as providing analogies to events of the present in past events, collective memory is strategic in character and capable of influencing the present. In other words, as we search for a means to impose a meaningful order upon reality, we rely on memory for the provision of symbolic representations and frames which can influence and organize both our actions and our conceptions of ourselves ${ }^{38}$.

Por último, el latido poético, que trasciende sin dificultad las dimensiones social y política de los textos, nos deja en la misma obra una señal inequívoca, descarnada, un tanto excesiva. Veamos un fragmento donde se reproducen parte de la nota que el gobernador Pérez Carballo le dejó a su esposa, horas antes de ser ejecutado -cedida por la familia y traducida al gallego-, y la contestación figurada de Juana Capdevielle, nacida del pulso íntimo de la autora, que en este caso expresa la trascendencia de un vínculo cuando se acerca el final:

\section{O amor é indestrutible}

Juana fuches o máis fermoso da miña vida. Onde estea e mentres poida pensar, pensarei en ti. Será como si estivésemos xuntos. Deixáchesme dito na noite do vintecatro de xullo antes de que te matasen. Paco, fuches o máis fermoso da miña vida. Onde estea e mentres poida pensar, pensarei en ti. Será como se esivésemos xunos. Dígoche na noite do dezaoito de agosto de 1936 antes de que me maten e pensó: quitaranme a vida, mais no me quitarán o amor porque o amor e indestrutible $e^{39}$.

Por su parte, Claudio Rodríguez Fer escribió "As costureiras", un conjunto de textos para teatro en memoria de Juana Capdevielle y las maestras socialistas Mercedes Romero Abellá (viuda del dirigente de la UGT coruñesa Francisco Mazariegos) y María Suárez, víctimas mortales de la represión franquista en Galicia ${ }^{40}$. Su adaptación teatral corrió a cargo de Paloma Lugilde, directora también de la obra que llevó por título Km 526, en referencia al punto exacto de la antigua carretera Madrid-A Coruña donde apareció el cadáver de Juana Capdevielle, trasladada allí desde Vilaboa (Culleredo) por sus verdugos, probablemente falangistas. La obra fue representada por el Taller de Arte Dramático de la Universidad de Santiago de Compostela (campus de Lugo) durante la IV Mostra Teatro Cidade de Lugo,

\footnotetext{
${ }^{37}$ Ibidem, pp. 158.

${ }^{38}$ Barbara MISZTAL, op cit, pp. 13.

39 Ibidem, pp. 158-159.

${ }^{40}$ Véase Unión Libre. Cadernos de vida e culturas, no 11 (2006), pp. 37-47.
} 
celebrada del 2 al 10 de mayo de 2006, año declarado de la Memoria Histórica por el Congreso de los Diputados.

En 2009, Rodríguez Fer publicó Ámote vermella, que contenía un bello y emotivo poema dedicado a Juana Capdevielle. Unos pocos versos para un abrupto viaje de ida y vuelta hacia el pasado, del que no se hace una lectura solamente en función de los estímulos y necesidades del presente (la resistencia ante los excesos del poder, la denuncia del vacío legal y la indiferencia ante las víctimas), sino que se contempla desde posiciones humanistas, en busca de referentes que consoliden identidades paralelas, imágenes secuenciadas, enlazadas, de pioneros y probables sucesores en la lucha por un mundo más justo:

\author{
A Juana Capdevielle \\ Dispararon á cabeza de mapoula, \\ mais medraron libres as silveiras \\ e nunca desfaleceron as ideas. \\ Dispararon ao corazón da rosa, \\ mmis volveron voar as bolboretas \\ e nunca feneceron os amores. \\ Matáronna co prexuizo sen xuizo, \\ Como quen queima xestas florecidas, \\ E por iso é patrimonio da xustiza. \\ Chamábase Juana Capdevielle, \\ Como podía chamarse a vida mesma: \\ morreu, como viviu, de amor e libaerdade. \\ En Rábade deixounos un carábel \\ para reinventar o amar, un xirasol \\ co que pacer a paz e unha violeta \\ para fabricar futuros mais muller ${ }^{41}$.
}

Tanto Carmen Blanco como C. Rodríguez Fer formaron parte del equipo de trabajo de la Vicerreitoria de Cultura de la Universidad de Santiago de Compostela (junto a varios investigadores vinculados al proyecto interuniversitario "As Víctimas, as voces, os nomes e os lugares"), encargado de organizar la exposición Vermellas: Chamábanlles "rojas". Borradas da historia, inaugurada en marzo de 2009 dentro de los actos organizados por el consorcio Lugo cultural, en virtud del convenio firmado entre la Universidad de Santiago, la Consellería de Cultura de la Xunta de Galicia, la Fundación Caixa Galicia y el Ayuntamiento y la Diputación de Lugo. El objetivo de esta exposición era restaurar la

${ }^{41}$ Tomado de RODRÍGUEZ FER, Claudio: Ámote vermella, Vigo, Edicións Xerais de Galicia, 2009. 
memoria de las mujeres que sufrieron en Galicia la violencia de la represión franquista durante la guerra civil ${ }^{42}$.

Otra expresión de la memoria cultural gallega como reconocimiento a la esposa del gobernador Pérez Carballo procedió también del mundo académico, en este caso de la Universidad de A Coruña, que le dio el nombre de Xoana Capdevielle al edificio que alberga la biblioteca central de esta universidad (campus de Elviña), en cuya fachada principal se han colocado recientemente (mayo de 2010) fotografías de los dos intelectuales madrileños.

Por su parte, la historiografía gallega -que, como toda producción histórica, se podría interpretar en clave de memoria crítica y objetiva- se ha acercado progresivamente a las figuras de Francisco Pérez Carballo y Juana Capdevielle. En los últimos años se ha puesto un mayor énfasis en algunos trazos de la biografía de la bibliotecaria madrileña, pues la figura del último gobernador republicano de A Coruña ha sido tratada a menudo tangencialmente, como pieza necesaria en un tablero contextual marcado por la derrota institucional republicana ante el éxito del golpe de estado en A Coruña ${ }^{43}$. En este punto, la identidad republicana e intelectual de Capdevielle, al igual que su condición de víctima de la violencia fascista más descarnada, han sido resaltadas en trabajos recientes sobre la represión de género en Galicia ${ }^{44}$.

Desde Madrid, la perspectiva de la memoria cultural ha dado también sus frutos en relación al caso que nos ocupa. Así, el escritor y periodista Rafael Torres publicó a finales de 2009 Nuestra Señora de la Cuneta, cuyo eje narrativo se trazó en torno a la muerte trágica de Juana Capdevielle, desde el que se proyectan síntesis biográficas de la bibliotecaria madrileña y de Francisco Pérez Carballo, complementado todo ello con pasajes relativos a la represión en la ciudad y la provincia de Lugo.

Muy interesante resulta la reconstrucción que hizo el autor de las últimas horas en la vida de Juana Capdevielle y de las circunstancias en que fue descubierto y reconocido su cadáver, para lo que contó con el relato de testigos directos de los hechos, entre ellos, el de dos hijos de José Penas, el médico encargado del examen forense del cuerpo de Juana en el probable lugar del crimen, al que acompañaron en aquella ocasión. Las conclusiones a las que llega Rafael Torres no modifican en esencia lo ya conocido, aunque la coherencia y la lógica del relato permiten descartar las hipótesis menos consistentes, iluminando así algunas zonas de sombra. En definitiva, se trata de una emotiva y

\footnotetext{
${ }^{42}$ En el catálogo de la exposición figura un interesante artículo -a cargo del equipo de investigadores del proyecto "As vítimas, as voces, os nomes e os lugares", integrado por Andrés DOMíNGUEZ ALMANSA, Gustavo HERVELLA GARCÍA, Chus MARTÍNEZ DOMÍNGUEZ y Antonio. SOMOZA CAYADO-, bajo el título "Da visualización social da muller á inmersión no terror: 1936. Golpe de estado, vítimas e memoria" (Catálogo de la exposición Vermellas: Chamábanlles "rojas"...) que identifica varias categorías simbólicas en la memoria de la represión de las mujeres en Galicia y diversos tipos de transmisión memorística, así como un primer informe sobre tipologías y perfil social de las represaliadas entre 1936 y 1939, que arroja una cifra inicial de 397, entre ejecutadas, encarceladas y procesadas sin condena.

${ }^{43}$ Por ejemplo, los trabajos del profesor Emilio Grandío revelan un acento crítico sobre la actuación de Pérez Carballo como gobernador civil, mientras que autores como Luis Lamela o Carlos Fernández Santander -su obra pionera sobre la guerra civil en Galicia es una referencia ineludible- valoran más positivamente el papel desempeñado por el joven discípulo de Azaña.

${ }^{44}$ Al artículo incluido en el catálogo de la exposición Vermellas: chamábanlles "rojas"...(citado en la nota número 41), se puede añadir, por ejemplo, Julio PRADA (ed.), Franquismo y represión de género en Galicia, Madrid, La Catarata, 2013.
} 
documentada aportación al dibujo de la memoria de una intelectual demócrata, que representaba un modelo de mujer inasumible para la atávica sociedad resucitada por un nuevo estado, asentado en la exaltación y práctica de la violencia y en la anulación del pensamiento crítico.

Juana Capdevielle San Martín. Bibliotecaria de la Universidad Central, es la aportación de Cristina Gállego Rubio (bibliotecaria también y funcionaria de los servicios centrales de la Biblioteca de la Universidad Complutense de Madrid) a fijar una trayectoria vital y profesional en la memoria colectiva de la generación de técnicos e intelectuales que protagonizó la modernización de la biblioteca de la Universidad Central durante la II República. En palabras de la autora:

En la recuperación de la memoria histórica de Juana Capdevielle, este libro pretende ser una aportación más que contribuya a la rehabilitación de su figura, cuyo entusiasmo como bibliotecaria de la Universidad de Madrid, junto al de sus compañeros de trabajo, cumplió con creces el sueño de trasformar una biblioteca que languidecía en otra moderna y adaptada a los nuevos tiempos ${ }^{45}$.

Este transparente y documentado ejercicio de rehabilitación de una figura intelectual y humana en el seno de una memoria colectiva, que podríamos denominar gremial por su estrecha vinculación a una determinada categoría profesional, se centra en la dimensión que adquiere la figura de Juana Capdevielle dentro del mundo cultural y universitario del Madrid republicano. La experiencia vital de Juana es contemplada, en especial, desde la perspectiva de su actividad académica, intelectual y profesional y de su papel en la transformación de la biblioteca universitaria en una moderna herramienta de cultura, más allá de su tragedia personal y de su rol de víctima, circunstancias que, por otra parte, tampoco obvia esta autora.

En el texto, se hace una aproximación a una biografía alejada de una adscripción política concreta. La solvente investigación de la autora no reveló indicio alguno en este sentido, en una época en la que las actas de las reuniones técnicas facultativas recogían frecuentes debates y posicionamientos políticos. Más allá de estas consideraciones, se nos habla de una Juana Capdevielle que se licenció en Filosofía y Letras (sección de Historia) por la Universidad de Madrid (1928) e ingresó por oposición, en junio de 1930, en el Cuerpo Facultativo de Archiveros, Bibliotecarios y Anticuarios, para ser destinada, en primera instancia, a la Biblioteca Nacional (septiembre de 1930) y, en 1931, a la Biblioteca de la Facultad de Filosofía y Letras de la Universidad Central de Madrid, y convertirse (en 1933) en la primera mujer en ostentar la jefatura de una biblioteca de facultad en la Universidad Central.

En la Universidad Central de Madrid, que alcanzó entonces una de las más altas cotas en la historia universitaria española, los años de la II República y las importantes reformas culturales y educativas inscritas en su ideario modernizador, trajeron, entre otras grandes realizaciones, la reestructuración de la hasta entonces diseminada biblioteca y su centralización bajo la dirección de Javier Laso de la Vega. En este contexto, Juana Capdevielle colaboraría en el traslado de los fondos de las bibliotecas del Decanato, del Instituto de San Isidro y de las escuelas superiores de Magisterio y Diplomática al nuevo edificio de la Facultad de Filosofía y Letras en la Ciudad Universitaria.

\footnotetext{
${ }^{45}$ Cristina GALLEGO RUBIO, Juana Capdevielle San Martín. Bibliotecaria de la Universidad de Madrid, Madrid. Editorial Complutense, 2010, pp. 144.
} 
Cristina Gállego también se refiere a la adscripción de Juana Capdevielle al Ateneo de Madrid, en calidad de socia-bibliotecaria, y a su papel como tesorera de la Asociación de Bibliotecarios y Bibliógrafos de España y miembro, junto con Martín Almagro, Juana Quílez o María Luisa Fuertes, del Seminario de Biblioteconomía de la universidad madrileña. Las recién creadas bibliotecas de hospital Juana Capdevielle participó muy activamente en la labor del servicio circulante de lectura constituido en los hospitales Clínico y de San José y Santa Adela-, constituyeron el objeto de la comunicación presentada por la bibliotecaria madrileña al II Congreso Internacional de Bibliotecas y Bibliografía en mayo de $1935 .{ }^{46}$ El discurso de inauguración de este evento, un ensayo titulado La misión del bibliotecario, fue leído en francés por el catedrático de metafísica de la Facultad de Filosofía y Letras de la Universidad de Madrid. Esta labor como articulista y ponente en congresos científicos no era nueva para Juana Capdevielle, pues años antes había publicado en Compluto, revista de la APED de Filosofía y Letras (FUE) de la Universidad de Madrid, un artículo titulado "La biblioteca de Filosofía y Letras", y presentado la ponencia titulada "El problema del amor en el ambiente universitario" -como ya se ha reseñado en otro lugar- en las Primeras jornadas eugénicas españolas ${ }^{47}$.

De igual modo, su interés por el estudio de la Clasificación Decimal Universal, sistema de ordenamiento y clasificación de los fondos que se estaba implementando entonces en la biblioteca de la Universidad Central, le llevó a solicitar y obtener una pensión de cuatro meses para viajar a Francia, Bélgica, Suiza y Alemania, concedida por la Junta de Ampliación de Estudios en 1935. En el capítulo final de su libro, Cristina Gállego Rubio traza también una semblanza de Francisco Pérez Carballo, del que destaca su sólida formación académica e intelectual, un activo importante para un profesor universitario destinado a brillar en las cátedras universitarias de derecho romano ${ }^{48}$.

En los últimos años las memorias culturales madrileñas han ido cristalizando de forma progresiva, conducidas desde universidades como la UCM y otras importantes instituciones vinculadas a una nueva sensibilidad política y ética, en varias exposiciones y jornadas conmemorativas, dedicadas a distintos centros universitarios y focos culturales de la etapa republicana. Algunas de ellas han tratado, desde diversos puntos de vista, la figura de Juana Capdevielle. Así, por ejemplo, la exposición Bibliotecas en Guerra, celebrada en la Biblioteca Nacional del 15 de noviembre de 2005 al 19 de febrero de 2006, reservó un espacio significativo a la bibliotecaria madrileña (una fotografía y un texto sobre su trayectoria vital) y a otros archiveros y bibliotecarios comprometidos en la difusión de la cultura durante los años treinta ${ }^{49}$. Con posterioridad, las Jornadas conmemorativas del LXXV aniversario del traslado de la Facultad de Filosofía y Letras al nuevo edificio de la Ciudad Universitaria de Madrid (mayo de 2008), donde se hizo un homenaje a su memoria, y, de manera especial, la espléndida exposición $L a$ facultad de Filosofía y Letras de Madrid durante la Segunda República. Arquitectura y universidad

\footnotetext{
${ }^{46}$ El titulo exacto de la comunicación, incluida en la sección dedicada a las bibliotecas populares, donde también participaron, entre otros, María Moliner y Gabriela Mistral, fue: "El fin que persiguen las bibliotecas de hospital, ¿debe ser distraer o instruir a los enfermos?”, en Actas del II Congreso Internacional de Bibliotecas y Bibliografía, 20- 30 de mayo de 1935, Madrid, Librería de Joaquín Barbazán, 1949, vol, 3, Bibliotecas Populares.

47 Juana CAPDEVIELLE SAN MARTíN, "La biblioteca de Filosofía y Letras”, en Compluto, Revista de la A.P.E.F.L (FUE), Madrid, núm. 1 (1932), pp. 14-15; y “El amor en el ambiente universitario”, en Enrique NOGUERA y Luis HUERTA (ed.), Libro de las primeras jornadas eugénicas españolas. Genética, eugenesia y pedagogía sexual, Tomo I, Madrid, Javier Morata Editor, 1934, pp. 174-192.

${ }^{48}$ Cristina GALLEGO RUBIO, op cit. pp.129.

49 “Juana Capdevielle”, en Biblioteca en guerra, Madrid, Biblioteca Nacional, 2005, pp.164.
} 
durante los años 30, celebrada en el Cuartel de Conde Duque de Madrid del día 18 de diciembre de 2008 al 15 de febrero de 2009, penetraron en la atmósfera cultural de la facultad y de la biblioteca donde estudió y trabajó hasta poco antes de su muerte. En concreto, en la exposición de Conde Duque se mostró una foto tamaño mural de Juana Capdevielle junto a un carro transportador de libros -que aún se conserva en la actual biblioteca de Filología de la $\mathrm{UCM}^{-50}$, tomada en la biblioteca del nuevo edificio de su facultad, en la Ciudad Universitaria, durante los trabajos de traslado y reubicación de los fondos ${ }^{51}$.

\section{CONCLUSIONES.}

El pujante papel de la memoria cultural, y de las memorias plurales proyectadas sobre el tiempo histórico de la República y la Guerra Civil, han dotado de significados y poderosos referentes de identidad a grupos de intelectuales, escritores y profesionales. Estos actores sociales se han empeñado en la labor de oposición simbólica, pero también activa y tangible, al establishment político y cultural, y en particular a las interpretaciones generadas por este para adaptar relatos y narrativas memorísticas a una línea oficial o a una ortodoxia mínimamente consensuada, que ha guiado con torpeza a la democracia española hasta el monólogo interior alcanzado en la última década. Así, las imágenes atemporales de Francisco Pérez Carballo, dirigente de la APED/FUE, militante político azañista y gobernador civil de A Coruña y Juana Capdevielle, intelectual independiente, víctima arquetípica de una violencia purificadora -entre otros muchos hombres y mujeres, pertenecientes a una generación sacrificada por sustentar la idea republicana-, se han convertido, al reflejarse en los canales donde fluye la dialéctica entre memoria e historia, en retratos intensos de demócratas avanzados a su época. Se trataría de símbolos que portaban y expresaban una noción de ciudadanía en su actividad política y social, también de víctimas que recordar, reivindicar y, finalmente, dignificar debidamente. Esto no quiere decir que todos los memory carriers examinados aquí (pensemos en los casos de Emilio González López, Ayala o García Valdecasas, por ejemplo) compartan una misma visión o perspectiva ideológica o cultural, al ejercer sus respectivas funciones en distintas secuencias temporales y políticas desde la Transición a nuestros días. Sin embargo, parece que la mayoría ha captado la relevancia simbólica cultural, identitaria, de estas figuras desde la atalaya implícita en cada uno de los presentes en que proyectaron sus respectivas miradas críticas o reivindicativas, presentes donde se mezclan o combinan intereses, conflictos y razones idealistas.

De ese modo, estos vectores del recuerdo han conectado con la historia personal de Francisco Pérez Carballo y Juana Capdevielle y convergido en la lógica compleja y selectiva de la memoria y el olvido, no siempre subordinada a componentes ideológicos estrictos. Por ello, es ahora el recuerdo de la bibliotecaria madrileña la que nos conduce al de su marido -a diferencia de lo sucedido hasta la Transición y aun hasta comienzos de este siglo-, perfecto cómplice intelectual y afectivo, para entablar

\footnotetext{
${ }^{50}$ Cristina GALLEGO RUBIO, ibidem, pp. 142.

${ }^{51}$ En el catálogo de esta exposición figuran varios artículos que hacen referencia a la figura de Juana Capdevielle. En la parte reservada a testimonios y documentos, se reproduce el artículo "La biblioteca de Filosofía y Letras", escrito por ella misma y publicado en 1932 en la revista de la A.P.E.F.L (FUE) Compluto (citado anteriormente). Catálogo de la exposición La Facultad de Filosofía y Letras de Madrid en la Segunda República. Arquitectura y universidad durante los años 30, Madrid, Sociedad Estatal de Conmemoraciones Culturales/ Ayuntamiento de Madrid/ Escuela de Arquitectura/ Fundación de Arquitectura COAM, 2008.
} 
una relación de la que surge también una memoria poliédrica, en permanente evolución como las distintas piezas de la identidad que alumbraría. 